\title{
Assessment of genetic diversity in the wheat genetic resources based on agricultural traits
}

Shin Myoung-Jae*, Ma Kyung-Ho, Lee Jung-Ro, Lee GiAn, Kim Seong-Hoon, Lee Kyung Jun, Raveendar Sebastin, Cho Gyu-Taek

National Agrobiodiversity Center, National Institute of Agricultural Sciences, RDA, Republic of Korea

*e-mail:smj1204@korea.kr

Wheat is one of the most widely consumed food crops in the world, in which many studies have been conducted on quantitative and qualitative traits, to improve its productivity. In this study, we have evaluated the genetic diversity of agricultural traits in the wheat genetic resources, which was collected and preserved at the National Agrobiodiversity Center to improve their utilization. A total of 450 wheat genetic resources, which was collected from Afghanistan, China and India were used in the study. The wheat genetic resources were planted and investigated with agricultural traits such as number of days to maturity, culm length, and ear length in between 2017-2018. Among the 450 wheat accessions, 16 accessions had the shortest number of days to maturity (209 days); the remaining 15 accessions except India K215537 were from China. In the culm length, China K141112 showed the shortest with 49.7 cm, while India K199831 was the longest with $152 \mathrm{~cm}$. Similarly, 10 Chinese accessions, in which China K250987 showed the longest ear length with $15 \mathrm{~cm}, 4$ Afghanistan accessions and an Indian accessions showed longest ear length. The mean number of days to maturity according to the collection area was 217.9 \pm 5.6 days in Afghanistan, $214.4 \pm 6.6$ days in China, and $216.3 \pm 6.3$ days in India. The mean culm length was $131.2 \pm 30.4 \mathrm{~cm}$ in Afghanistan, $95.2 \pm 52.0 \mathrm{~cm}$ in China, $111.4 \pm 24.0 \mathrm{~cm}$ in India. Similarly, the ear length was $10.1 \pm 3.0 \mathrm{~cm}$ in Afghanistan, $9.8 \pm 3.5 \mathrm{~cm}$ in China and $9.3 \pm 2.2 \mathrm{~cm}$ in India. The distribution of agricultural traits in the wheat genetic resources showed wide genetic diversity in Chinese resources, which is probably due to the China's various climatic zones. The results of this experiment could provide basic information for the development of wheat varieties, such as lodging tolerance including early-maturity varieties. 